\title{
GÊnERO E RAÇA: QUESTÕES COMPARATIVAS E Elementos PARA O CAmPO de PEnSAmEnTO SOCIAL a PARTIR de CASA-GRAODE E SEnZAL'
}

\author{
Fernando José Ciello ${ }^{8}$
}

\section{RESUMO}

O presente trabalho tem como principal objetivo rever aspectos referentes a articulação gênero-raça na obra Casa-Grande e Senzala (1933), de Gilberto Freyre. Partindo de uma comparação com trabalhos mais contemporâneos sobre a temática, o artigo pretende expor aspectos comparativos e elementos que apresentem as continuidades e rupturas do pensamento de Gilberto Freyre com relação a certos traços do pensamento social brasileiro ligados a estas categorias. Aponta-se, ao final, a existência de uma evidente relevância do tópico da "morenidade" brasileira, bem como uma exaltação da miscigenação, que vem acompanhadas em nosso contexto por conteúdos fortemente generificados e que atravessam diversas dinâmicas sociais brasileiras.

Palavras-chave: Gênero. Raça. Gilberto Freyre. Mariza Corrêa. Pensamento Social.

O presente trabalho tem como principal objetivo revisitar elementos que remetem ao campo de estudos de gênero na obra Casa-Grande e Senzala, de Gilberto Freyre (2002, 2011 [1933]) e compará-los com outros artigos (CORREA, 1996, 2000) que apresentam articulações analíticas das categorias de gênero e raça. A intenção principal é explorar aspectos da obra de Gilberto Freyre que dizem respeito a este cruzamento, tendo como ponto de partida o fato de que se encontra na obra uma reflexão que articula estas categorias, ainda que de modo não explícito, e ao mesmo tempo apontar elementos e questões comparativas

7 O presente artigo foi escrito originalmente para a disciplina de Antropologia do Pensamento Social Brasileiro, no âmbito do Programa de pós-graduação em Antropologia Social da Universidade Federal do Paraná (DEAN/ UFPR), ministrada pela Professora Dra. Rosangela Digiovanni, no primeiro semestre letivo de 2011.

8 Graduado em Ciências Sociais (2009) pela Universidade Estadual do Oeste do Paraná (UNIOESTE). Aluno do programa de Pós-graduação em Antropologia Social da Universidade Federal do Paraná (DEAN/ UFPR). E-mail: fernando.ciello@gmail.com. 
para o debate que envolve estes temas nas Ciências Sociais. Não se busca aqui uma discussão exaustiva sobre a temática, mas sim, apresentar questões que ao longo da história das Ciências Sociais têm sido mobilizadas para interpretar o Brasil e que acabam por ter em Gilberto Freyre um importante referencial. Parto aqui, portanto, de uma discussão específica sobre Gênero e Raça no contexto destes trabalhos que, embora histórica e teoricamente distantes, marcam momentos interessantes do debate. Como é de notório reconhecimento pelas Ciências Sociais brasileiras o trabalho de Freyre em Casa-Grande e Senzala se remete em inúmeros aspectos ao campo da antropologia, tendo apontado, como veremos ao longo do texto, para questões cruciais do período intelectual do autor, tais como a dita passagem "raça-cultura" e a problemática da miscigenação, crucial no pensamento social brasileiro. Por este motivo os artigos aos quais me referi anteriormente e para os quais o foco principal do texto foi dirigido são oriundos do campo da Antropologia Social brasileira que, ao longo dos anos, tem se debruçado sobre a obra de Freyre de diferentes maneiras e com importantes pontos de reflexão.

No trabalho de Gilberto Freyre, representações diversas sobre papéis de gênero estão presentes sem, evidentemente, uma teorização em torno dos "estudos de gênero" - que surgem enquanto tais, décadas mais tarde. Em linhas gerais, o foco da obra são as consequências que o modo patriarcal de colonização imprimiu na formação da população brasileira. Por outro lado, em Mariza Corrêa, questões de gênero e suas articulações com as relações raciais no Brasil são abordadas de modo mais central, ainda que num espaço mais curto. As discussões do texto da autora apontam para a inseparabilidade entre gênero e raça no contexto brasileiro, dada a determinação mútua de ambas as categorias em alguns contextos. Seguindo a pista deixada por Corrêa (1996), este texto se concentrará numa discussão ensaística sobre a temática das representações de gênero e raça, tomando-as de modo bastante genérico e, portanto, sem interrogar suas histórias etimológicas ou seus estatutos epistemológicos. Pretende-se, ao final, ter levantado questões relevantes dos textos dos autores e apontar rupturas 
e continuidades entre os mesmos, ao mesmo tempo em que algumas considerações de rendimento analítico sejam apontadas.

Parece impossível iniciar este debate sem falar de Casa Grande e Senzala (1933), de Gilberto Freyre (1900-1987), não somente pelo aspecto cronológico, mas porque muitas discussões presentes no pensamento social brasileiro bebem diretamente em construções presentes na obra do autor. É importante assinalar que neste período intelectual diversos autores ${ }^{9}$ se debruçavam sobre a complicada tarefa de compreender que ideia de nação e que perspectivas para a modernização se encontravam a disposição do país. A discussão que se encontra em Casa-Grande e Senzala se insere neste mesmo espectro, mas, diferentemente de outros trabalhos, desenvolve um tipo de discussão sobre o período colonial do país que, por um lado, se aproxima das questões políticas e econômicas próprias do sistema e, por outro, põe em discussão também o "intimismo" do próprio processo de miscigenação, as dinâmicas que - no cotidiano da vida da casagrande e da senzala - tornaram possível a articulação entre estas duas esferas. Diz o autor:

A casa-grande, completada pela senzala, representa todo um sistema econômico, social, político: de produção (a monocultura latifundiária); de trabalho (a escravidão); de transporte (o carro de boi, o bangüê, a rede, o cavalo); de religião (o catolicismo de família, com capelão subordinado ao pater famílias, culto dos mortos, etc.); de vida sexual e de família (o patriarcalismo polígamo); de higiene do corpo e da casa (o "tigre", a touceira de bananeira, o banho de rio, o banho de gamela, o banho de assento, o lava-pés); de política (o compadrismo). (2002: 12).

Dentre as teses defendidas para a ocorrência desse complexo sistema social, o autor argumenta sobre o momento histórico propício no qual se encontrava a Coroa Portuguesa e do patriarcalismo rural escravocrata típicos do processo de conquista. Argumenta ainda - e esta é uma tese forte para o autor

9 Sérgio Buarque de Holanda (1936), Caio Prado Junior (1942), entre outros. 
sobre as relações raciais que se produzirão no Brasil - sobre a influência do meio físico nos processos gestados entre a casa-grande e a senzala, na modificação da própria raça vinda de além-mar. Gilberto Freyre admite, assim, a existência de uma tendência do meio físico (e também bioquímico, diz o autor) a "recriar à sua imagem os indivíduos que the cheguem de várias procedências" (2002: 11). De início o autor expõe a necessidade de distinguir raça e cultura e de não confundir, assim, o que considera atributos próprios da raça com características herdadas da experiência cultural e do meio. $\mathrm{O}$ autor defende, nas breves palavras do prefácio, que o encontro entre as raças - considerado, então, como responsável pela falta de robustez da população brasileira - na verdade "resolveu" a distância presente entre a casa-grande e a senzala:

A miscigenação que largamente se praticou aqui corrigiu a distância social que doutro modo se teria conservado enorme entre a casa-grande e a mata tropical; entre a casa-grande e a senzala. O que a monocultura latifundiária e escravocrata realizou no sentido de aristocratização, estremando a sociedade brasileira em senhores e escravos, com uma rala e insignificante lambujem de gente livre e sanduichada entre os extremos antagônicos, foi em grande parte contrariado pelos efeitos sociais da miscigenação. (FREYRE, 2002: 9).

A miscigenação assume um novo lugar para Gilberto Freyre. Os debates sobre raça, típicos do período intelectual do autor, envolviam uma descrição dos problemas de eugenia e, nas palavras de Freyre, de questões envolvendo "traços (...) hereditários preponderando sobre outras influências" (2002: 7). Ao propor, contudo, um espaço para pensar a miscigenação também a partir da experiência social (ou, da preponderância desta sobre aqueles) e, no caso do autor, da empresa econômica, cultural e política que representou o sistema de casa-grande no período colonial, Gilberto Freyre se alia a uma percepção antropológica da problemática e contribui para desmontar a relevância da noção de raça nas análises de Brasil. Comentando brevemente a temática, em texto de abertura de edição recente da obra, Fernando Henrique Cardoso afirma que a visão antirracista de Freyre se expressa em sua percepção de que o negro se constrói como "orgiástico por sua situação social de escravo e não por consequência da 
raça ou fatores intrinsecamente culturais" (2011: 20). ${ }^{10}$ Quando fala da falta de robustez da população brasileira (Freyre, 2002: 10), entre outros atributos, é ao problemático sistema latifundiário de monocultura e às relações sociais nele estabelecidas que Gilberto Freyre recorre e não - pelo menos não somente - aos atributos bio-psico-sociais das raças envolvidas no sistema.

Ganham extrema importância no trabalho do autor, neste contexto de aproximação da cultura, os aspectos da vida íntima e do cotidiano no Brasil colonial: relatos de viajantes, relatos familiares, cartas religiosas, entre outras fontes. Segundo o pesquisador Claudio Marcio Coelho (2008: 133) esta utilização de fontes então menosprezadas no âmbito da pesquisa social é marcante na obra de Gilberto Freyre e, de modo geral, a obra representa uma inovação para a pesquisa histórica e social. É neste recurso metodológico à intimidade que se pode localizar - ou, diria, levantar questões - a respeito da percepção que a obra produz sobre representações de gênero. No mesmo prefácio, já mencionado anteriormente, diz Freyre:

No Brasil, as relações entre os brancos e as raças de cor foram desde a primeira metade do século XVI condicionadas, de um lado pelo sistema de produção econômica - a monocultura latifundiária; do outro, pela escassez de mulheres brancas, entre os conquistadores. (2002: 8)

E continua, adiante, afirmando que "(...) a escassez de mulheres brancas criou zonas de confraternização entre vencedores e vencidos, entre senhores e escravos." (Freyre, 2002: 9). As representações, como se nota, sobre mulher (e sobre homem, como se poderá observar mais adiante) estão imbricadas nas relações produzidas (e produtoras) da conjuntura social no "complexo casa-grande e senzala". O contato entre brancos e "raças de cor" foi mobilizado, neste sentido, além do modelo político-econômico, pela falta de mulheres brancas. $O$ autor apresenta a mulher branca (européia) como um destino considerado ideal pelo

10 Fernando Henrique Cardoso adiciona na sequência deste comentário a informação de que, não obstante, Gilberto Freyre construa uma imagem idealizada do negro, exaltada a diversos patamares, em contrapartida, o "elemento índio" teria sido subsumido e reduzido a participação como "coletor" no Brasil colonial. 
empreendedor colonial, mas ao mesmo tempo, a mulher como um ente genérico, sujeito do sexo feminino, com o qual invariavelmente o contato viria a ocorrer ${ }^{11}$. Gilberto Freyre defende em vários momentos da obra a ideia de que a colonização portuguesa foi a que se deu dentre as outras, em qualquer canto, de modo mais híbrido. As teses de mobilidade ${ }^{12}$, miscibilidade e aclimatabilidade ${ }^{13}$, defendidas pelo autor, seriam responsáveis pela fácil adaptação dos portugueses a qualquer lugar que fossem. Ainda que as três, juntas, caracterizem o perfil colonizador português, a tese da miscibilidade, porém, pode ser a mais interessante para o debate aqui produzido. Diz o autor:

Foi misturando-se gostosamente com mulheres de cor logo ao primeiro contato e multiplicando-se em filhos mestiços que uns milhares apenas de machos atrevidos conseguiram firmar-se na posse de terras vastíssimas e competir com povos grandes e numerosos na extensão de domínio colonial e na eficácia da ação colonizadora. (2002:39). [grifos meus]

Em outro momento, diz ainda:

A escassez de capital-homem, supriram-na os portugueses com extremos de mobilidade e miscibilidade: dominando espaços enormes e onde quer que pousassem, na África ou na América, emprenhando mulheres e fazendo filhos, numa atividade genésica que tanto tinha de violentamente instintiva da parte do individuo quanto de política, de calculada, de estimulada por evidentes razões econômicas e políticas da parte do Estado. (2002: 37). [grifos meus]

11 "Mesmo que não existisse entre a maior parte dos portugueses evidente pendor para a ligação, livre ou sob a benção da Igreja, com as caboclas, a ela teriam sido levados pela força das circunstâncias, gostassem ou não de mulher exótica. Simplesmente porque não havia na terra quase nenhuma branca (...)". (FREYRE, 2002: 120).

12 "A mobilidade foi um dos segredos da vitória portuguesa; sem ela não se explicaria ter um Portugal quase sem gente, um pessoalzinho ralo, insignificante em número - sobejo de quanta epidemia, fome e sobretudo guerra afligiu a Península na Idade Média - conseguindo salpicar virilmente do seu resto de sangue e de cultura populações tão diversas e a tão grandes distâncias umas das outras; na Ásia, na África, na América, em numerosas ilhas e arquipélagos." (FREYRE, 2002:37).

13 "Nas condições físicas de solo e de temperatura, Portugal é antes África do que Europa. O chamado 'clima português' de Martone, único na Europa, é um clima aproximado do africano. Estava assim o português predisposto pela sua mesma mesologia ao contato vitorioso com os trópicos: seu deslocamento para as regiões quentes da América não traria as graves perturbações da adaptação nem as profundas dificuldades de aclimatação experimentadas pelos colonizadores vindos de clima frio." (FREYRE, 2002:39). 
Ao passo em que a mulher é tida algo como uma mercadoria ou produto da terra, o homem é enaltecido pelos atributos da virilidade e do atrevimento. $O$ contato entre conquistador e as mulheres autóctones é lido por Gilberto Freyre, não se pode negar, a partir de uma espécie de determinismo biológico (bastante típico para a época): o homem e seu violento instinto de procriação, a mulher e sua condição de subalternidade. O texto deixa evidente em vários momentos a produção que se faz no contexto brasileiro, na perspectiva de Freyre, de uma associação entre papéis de gênero e supostas características raciais. $O$ contato com a mulher indígena e a mulher negra aparece, no contexto da obra, como contingência e ao mesmo tempo como elemento crucial na construção das relações sociais do sistema patriarcal-escravocrata. Contingência, pois à mera falta de mulheres brancas foi como se qualquer mulher servisse, portanto fazendo o conquistador incorrer no relacionamento com indígenas e escravas. Elemento importante, pois sem o borrão racial e cultural criado no contato entre brancos e as raças de cor o próprio desenrolar da história contada por Freyre não seria o mesmo, nem as mesmas seriam suas teses sobre o desenvolvimento da família brasileira. É na mulata, no entanto, que repousam muitas construções do livro e é também sobre sua posição social que, demonstra Freyre, foram construídas diversas representações culturais. Diz o autor:

Pode-se, entretanto, afirmar que a mulher morena tem sido a preferida dos portugueses para o amor, pelo menos para o amor físico. A moda de mulher loura, limitada aliás às classes altas, terá sido antes a repercussão de influências exteriores do que a expressão de genuíno gosto nacional. Com relação ao Brasil, que diga o ditado: 'Branca para casar, mulata para f..., negra para trabalhar', ditado em que se sente, ao lado do convencionalismo social da superioridade da mulher branca e da inferioridade da preta, a preferência sexual pela mulata. Aliás o nosso lirismo amoroso não revela outra tendência senão a glorificação da mulata, da cabocla, da morena celebrada pela beleza dos seus olhos, pela alvura dos seus dentes, pelos seus dengues, quindins e embelegos muito mais do que as 'virgens pálidas' e as 'louras donzelas'(FREYRE, 2000: 38-39). [grifos meus].

No entanto, como vimos, o trabalho de Gilberto Freyre mobiliza conjuntamente diversas esferas explicativas. Em primeiro plano está a produção de um sistema econômico e na retaguarda está todo um arcabouço de caracteres 
culturais informando a produção de relações políticas. Representações sobre mulheres brancas e mestiças; intervenção do Estado; estimulações econômicas; influências climáticas; aspectos da vida cotidiana estão assim imbricadas num mesmo complexo sistema social. Por um lado se constrói um discurso sobre nação, os 'gostos nacionais' e, por outro, a reiteração de padrões de gênero e, ainda que sem pretendê-lo, a colocação da raça par a par com o tema de gênero em sua discussão sobre o Brasil. Por outro lado (ou pelo mesmo lado) a representação de mulher aparece importantemente marcada no contexto da obra e é feita de modo que esta seja, de modo geral, uma personagem em todo o sistema casa-grande - senzala. Esteja relacionada à propensão portuguesa a "emprenhar várias mulheres" ou à suposta vocação da cabocla e da mulata para atrair o sexo oposto, as construções às quais está sujeita esta mesma mulher, como vimos, são variadas e contradizem o lugar secundário que a principio se poderia crer estar sendo dado a mulher em Casa-Grande e Senzala.

Como mencionado anteriormente, este contato "forçoso" entre o conquistador e a mulher do Brasil acabou, aos poucos, criando um contexto de aproximação entre a casa-grande e a senzala e diminuindo distancias sociais que o próprio sistema poderia ter criado. Gilberto Freyre depreende disto a configuração de "relações harmoniosas" entre as raças que teriam contribuído para o aproveitamento das características diversas dos povos que se encontraram. De acordo com o autor, "organizou-se uma sociedade cristã na superestrutura, com a mulher indígena, recém-batizada, por esposa e mãe de família; e servindo-se em sua economia e vida doméstica de muitas das tradições, experiências e utensílios da gente autóctone". (FREYRE, 2002: 119).

No segundo capítulo da obra, quando discute sobre as condições de "amalgamento de raça e cultura", o autor afirma que o Brasil foi "região onde o elemento europeu nunca se encontrou em situação de absoluto e indisputado domínio" e que, por mais rígidos que fossem os portugueses, eles foram forçados pelo "meio geográfico e pelas exigências da política colonizadora a competirem com aqueles [outros elementos étnicos] numa base aproximadamente igual." 
(FREYRE, 2002: 119). A aproximação racial, contudo, que inicialmente teria se dado em função da escassez da mulher branca, no século seguinte ao da chegada dos conquistadores, como diz Gilberto Freyre, passa a se dar de modo livre. Os homens passariam, ao longo do século XVII, a buscar as mulheres índias (sobretudo), por "decidida preferência sexual" (2002: 119). Pelo menos dois argumentos são mobilizados nesse sentido: um deles retoma a discussão sobre uma maior sensualidade da mulher indígena, fazendo o autor considerar o ambiente em que chegou o branco como um ambiente de "intoxicação sexual" (p.120). O outro diz respeito a um interesse por parte da mulher indígena de terem filhos que pertencessem à raça superior (2002: 120).

O europeu saltava em terra escorregando em índia nua; os próprios padres da Companhia precisavam descer com cuidado, senão atolavam o pé em carne. Muitos clérigos, dos outros, deixaram-se contaminar pela devassidão. As mulheres eram as primeiras a se entregarem aos brancos, as mais ardentes indo esfregar-se nas pernas desses que supunham deuses. Davam-se ao europeu por um pente ou um caco de espelho. (FREYRE, 2002: 121). [grifos meus].

O que Freyre descreve no livro é um intenso processo de hibridização no Brasil no período colonial, manifestada no contato entre as diversas culturas-raças que aqui se encontraram. Talvez por isto, o aspecto mais duradouro que CasaGrande e Senzala talvez tenha ajudado a construir no imaginário brasileiro, se refere a ideia de uma "democracia racial" no contexto das relações raciais no Brasil. Sem pretender produzir uma discussão apurada a esse respeito, muito menos traçar uma genealogia da expressão, remeto-me aqui à ideia de democracia racial para ilustrar a ideia produzida por Gilberto Freyre de que haveria um potencial atenuador de conflitos sociais e políticos no regime casagrande e senzala brasileiro. Ao mesmo tempo, como pode ser observado nos trechos acima transcritos, o regime escravocrata brasileiro tem uma particularidade evidente e que foi acentuada no trabalho freyreano: seu amplo (e complexo) potencial de miscibilidade e, nos termos do autor, de aproximação de opostos estruturais (senhor - escravo; negro - branco), o que compõe - também - 
o espectro da suposta democracia racial brasileira. ${ }^{14}$ Num breve trecho de artigo publicado, a antropóloga Ana Pacheco fornece uma observação interessante sobre os comentários acima:

(...) haveria uma moral sexualizante "desenfreada" dos escravos, que se caracterizava pela passividade política e por práticas de masoquismo sexual. O "sadismo do branco", o masoquismo da índia e da negra" e a "submissão do moleque de cor ao senhor" revelavam, segundo Freyre, o caráter nacional do brasileiro, elástico, propenso também à mistura, ou como diria Da Matta, levavam a "triangular", intermediar e negociar as posições polares do sistema racial brasileiro, sem entrar em conflitos abertos. (2006: 161-162).

A despeito dos longos debates, favoráveis ou desfavoráveis, a respeito da democracia racial, a questão parece girar em torno de - como chamou Mariza Corrêa (1996) - uma suposta vocação brasileira para a morenidade, encontrada no horizonte da forte miscigenação presente no país, alegada desde, pelo menos, Gilberto Freyre e seu Casa-grande e Senzala (2002 [1933]). Ainda que num contexto intelectual totalmente distinto, Corrêa retoma a discussão em torno do tema das relações raciais, presente em Casa-grande e Senzala, propondo uma análise conjunta entre dois complexos temas (gênero e raça) partindo da figura, não menos complexa, da mulata. A autora retoma muitos dos debates que estavam em voga no trabalho de Gilberto Freyre, embora não se refira diretamente ao autor. Tomando, porém, a ideia de uma exaltação da mulata como dado e levando em conta as considerações de Gilberto Freyre sobre as relações raciais produzidas a partir de nossa grande miscigenação e nossa democracia

14 Numa consulta rápida sobre referências para um debate sobre democracia racial, vislumbrase a produção do sociólogo Antônio Sérgio Alfredo Guimarães. Cf. GUIMARÃES $(2005,2006)$. De acordo com o autor a ideia de democracia racial não tem em Gilberto Freyre uma referência exclusiva e deve ser tomada como uma ocorrência historicamente referenciada no momento em que surge no contexto brasileiro. Paralelamente a isso, deve-se observar, como lembrou David Lehmann (2008), que a expressão propriamente dita, jamais teria sido usada por Gilberto Freyre para falar de um tal estado de coisas no Brasil, mas de uma maior efetivação da democracia brasileira no quesito 'racial'. Ao mesmo tempo, autores da Antropologia Social (Yvonne Maggie, Peter Frey, Lilia Schwarcz) em diferentes momentos de suas discussões tem contribuído para uma percepção da ideia de democracia racial não somente como um mito, mas como uma construção que concretamente influencia a vida dos sujeitos e orienta a sociedade brasileira em termos do debate sobre preconceitos raciais. 
racial, torna-se evidente, assim me parece, que o autor levantou temas que reverberaram (e ainda reverberam) nas discussões sobre Brasil.

Existe, assim, ainda que de modo não explícito uma centralidade na miscigenação e - especificamente - na descrição da mulata em Casa Grande e Senzala. Reside aí, precisamente, a ideia desenvolvida por Mariza Corrêa com relação a "invenção" da mulata. Citando vários autores (Gregório de Matos, Aluísio Azevedo, Jorge Amado, entre outros) Corrêa recorda que em nossa literatura, em nosso teatro, no rádio, na televisão, reiteradamente constrói-se a representação da mulata como objeto de desejo, como possuidora - diria Freyre - de dengues e embelegos; "bonita e graciosa, dengosa e sensual", conforme lembrou Mariza Corrêa (1996: 36). Esta representação, ou melhor, esta construção da mulata como objeto de desejo encontra fundação, como defenderá a autora, não somente nesta forma específica de se referir à mulher, mas a um complexo esquema que produz relações raciais específicas e que aponta para uma aparente inseparabilidade entre os temas "raça" e "sexualidade". Falando de sua proposta diz a autora:

\begin{abstract}
Não se trata (...) de falar da perspectiva do sujeito, mas sim da construção do sujeito enquanto objeto de discursos médicos, literários e carnavalescos. Isto é, de pensar como a invenção dessa categoria, para além de sua existência empírica, pode contribuir para questionarmos nossa forma habitual de tratar seja das relações de raça, seja das relações de gênero. (CORRÊA, 1996: 38).
\end{abstract}

Como se sabe, por um longo período, o debate sobre as consequências da miscigenação na sociedade brasileira foi constante e produziu diversas interpretações. Tais debates orientaram e mobilizaram, em especial, as ideias de nação, nacionalidade, modernidade, que se avolumaram entre os séculos XIX e $X X$. Assim como aconteceu com a constituição de outros saberes no mesmo período, como é o caso da medicina ou da própria psiquiatria ${ }^{15}$, debates científicos

15 Conferir Magali Engel (1997), Maria Clementina Pereira Cunha (1989), Yonissa Marmitt Wadi (2002), entre outros. 
diversos também tiveram como alvo atributos raciais dos sujeitos. Com relação ao tema diz Corrêa (1996: 43):

$\mathrm{Na}$ classificação cientifica do século dezenove, brancos e negros se opunham como categorias discretas e sua mistura, portanto, tinha um efeito de paleta de pintor: tonalidades correspondiam também a atitudes, ou comportamentos esperados de uma 'mistura', não só de cores como de disposições inatas, herdadas.

O que é relevante, porém, acompanhando a discussão da autora, são os argumentos mobilizados para discutir padrões de gênero no âmbito destes debates sobre relações raciais. As classificações científicas cedem lugar, de acordo com a discussão de Corrêa (1996), para uma cada vez mais complexa hierarquização das relações entre raça e gênero. A discussão a partir de oposições estruturais e da hierarquização interna destas mesmas oposições é constante no texto de Corrêa, o que pode evocar uma certa inspiração estruturalista na discussão que promove no artigo em questão. No caso de uma definição de papéis masculinos argumenta a autora que sexualmente o mestiço era quase sempre classificado a partir de um sinônimo com a ideia de efeminado, numa oposição explícita ao branco como heterossexual. (1996: 43). A mulata, de forma semelhante, tem sua feminilidade classificada a partir de uma oposição com a mulher branca, como referencial para o discurso de feminilidade (1996: 44).

Para ser sintético, existiria, pelo menos para efeito analítico, uma oposição, tomada como dada, entre homens e mulheres (homem : mulher). A esta hierarquização somar-se-ia, por sua vez, o argumento racial, produzindo nova hierarquização interna no continuum masculino/feminina. Seja como for, conforme argumenta a autora, o mulato teria alcançado um branqueamento rápido em sua posição no continuum, aproximando-se desta vez do polo masculino (1996: 44). Mesma situação não ocorreria com a mulata, cujas representações permaneceriam ainda fortemente vinculadas a uma representação de amoralidade, em oposição à conjugalidade da branca.

Ao mesmo tempo, conforme argumenta Mariza Corrêa (1996), uma descrição apurada da posição estrutural da mulata no horizonte social brasileiro 
não se encontra nem na ideia de uma polaridade alegada entre negros e brancos, nem na ideia de continuum entre um e o outro polo; a mulata, ao contrário, estaria no "encontro". Isto é, a ideia de continuum (que também esteve presente para debater questões envolvendo relações raciais e mediunidade nas religiões de inspiração espírita, cf. CAVALCANTI, 1983, 2005) implica na construção de gradientes entre os polos branco e negro, como categorias pranchadas, e na criação de classificações sociais diversas entre os opostos. A ideia de continuum, como no estudo das religiões mediúnicas, é refutada também por Corrêa. A autora defende que diferentemente da "fluidez" alegada pelos defensores da ideia de um continuum, a mulata ocupa um lugar bastante definido entre os polos negro e branco, qual seja o do "encontro entre raças", a mulata - continua a autora - "não é uma definição passível de negociação". (Corrêa, 1996: 47-48).

Ainda sobre influências na vida sexual da população, uma ideia final, de algum rendimento analítico pode se mostrar interessante. A questão da homossexualidade aparece muito brevemente abordada no texto de Gilberto Freyre e em contextos bastante específicos, ora se referindo ao universo indígena, ora se referindo ao universo afro-brasileiro. Seja como for, como se sabe, mereceram atenção específica em Casa-Grande e Senzala as influências que negros e indígenas teriam causado na 'família brasileira'. Mencionando os rituais de iniciação dos meninos indígenas ao atingirem a puberdade, o autor comenta:

Durante a segregação o menino aprendia a tratar a mulher de resto; a sentir-se sempre superior a ela; a abrir-se em intimidades não com a mãe nem com mulher alguma, mas com o pai e com os amigos. As afinidades que se exaltavam eram as fraternas, de homem para homem; as de afeto viril. Do que resultava ambiente propício à homossexualidade. (FREYRE, 2002: 159).

Como em tudo o mais na obra do autor, existe nos trechos acima mencionados uma forte propensão a pensar diferenças ou aspectos raciais - nisso aproximando-se de Franz Boas, seu mestre quando de seu período de estudos no EUA - como produtos culturais de adaptações ao ambiente e a contextos climáticos e biológicos. Sem adentrar nos meandros dessa discussão, o que está presente, também, é a representação amplamente difundida do indígena como 
efeminado e não cumpridor de suas tarefas sociais. Por outro lado, parece haver, naquilo que tange aos indígenas, uma atenuação do suposto 'horror' que a homossexualidade entre os primitivos poderia suscitar, o que faz reavaliar a ideia precipitada que se poderia formular de uma percepção preconceituosa genérica do autor com relação a homossexualidade. Gilberto Freyre, com rigor suficientemente antropológico, lembra o ritual da couvade, do prestígio dos ditos efeminados nas práticas de magia sexual, lembra o fato de que muitos homossexuais ou bissexuais na antiguidade teriam sido reconhecidos como chefes em suas respectivas tribos e, ainda, da contribuição que a atividade homossexual ou bissexual teria legado à cultura de modo geral como aspectos complexificadores e enriquecedores. (cf. Freyre, 2002: 142-143).

Diferente do indígena, porém, o negro teria exercido uma influência mais perniciosa e teria sido responsável não só pela iniciação sexual dos mancebos portugueses, mas como participantes, entre outros, de um processo de sifilização da população brasileira no período escravista. Uma vez contaminadas pelos próprios senhores, as negras, nas senzalas, tornar-se-iam grandes disseminadoras de gonorréria e sífilis (Freyre, 2002: 329). Ao mesmo tempo, a corrupção sexual seria produto não somente da mulher negra, mas do próprio sistema escravista e, por conseguinte, também da escrava índia (Freyre, 2002: 237). Neste particular, a construção freyreana é bastante interessante, e passa a impressão de uma maior crítica político-ideológica ao sistema casa-grande/ senzala do que no resto da obra. De acordo com Gilberto Freyre (2002: 332) não se trata tanto de que o negro teria trazido consigo o conteúdo da corrupção, mas que ele se teria tornado um elemento "patogênico" em função do próprio sistema escravista, que impunha uma relação de inferioridade com os portugueses. A libertinagem do branco, portanto, era como um produto dos próprios limites que 'seu sistema' impunha. Diz o autor: "Não era o negro, portanto, o libertino: mas o escravo a serviço do interesse econômico e da ociosidade voluptuosa dos senhores." (Freyre, 2002: 331). Argumenta, por fim: 
Nas condições econômicas e sociais favoráveis ao masoquismo e ao sadismo criadas pela colonização portuguesa (...) e no sistema escravocrata de organização agrária do Brasil; na divisão da sociedade em senhores todo-poderosos e em escravos passivos é que se devem procurar as causas principais do abuso de negros por brancos, através de formas sadistas de amor que tanto se acentuaram entre nós; e em geral atribuídas à luxúria africana. (FREYRE, 2002: 332)

Mariza Corrêa (1996:43), por sua vez, lembra em seu texto que ao longo do século XIX as classificações científicas opunham negros e brancos. No que diz respeito ao homem, a autora retrata a ideia de que quase sempre o mestiço era tido como um sinônimo de efeminado ou, como no termo de época, como pederasta passivo, numa oposição não explicitada ao branco como heterossexual. Embora não formulada pela autora, a problemática de um "racismo científico", que implica na busca de critérios científicos ou na tipificação cultural da raça, está muito próxima do tema da degeneração, que perpassou as discussões raciais brasileiras e fomentou a crença de que a miscigenação seria, em si, um erro, pelo seu potencial de degeneração dos aspectos raciais inatos. (Cf. PACHECO, 2006: 159). O "erro", por sua vez, acaba mobilizando a própria temática da sexualidade, fazendo gênero e raça se tornarem categorias muito próximas. Como no caso do mestiço como pederasta, existe um recurso - 'implícito', como afirma Corrêa - de se recorrer à classificações sociais vigentes como uma forma de hierarquizar negros e brancos - homens e mulheres. (1996: 43). O mulato segundo Corrêa teria, porém, alcançado um branqueamento mais efetivo de sua posição social no continuum, diferentemente da mulata, que permaneceria para sempre numa posição intermediária e, portanto, de difícil classificação.

Em O Mistério dos orixás e das bonecas: raça e gênero na antropologia brasileira (CORRÊA, 2000), a autora relata duas situações que seriam emblemáticas sobre a conexão entre relações raciais e relações de gênero, num período bem mais tardio do que este que descrevi até aqui. A primeira diz respeito a uma feira ocorrida em Portugal, em 1940, para tratar da história do mundo português e, para a qual, o Brasil havia sido convidado a atuar como expositor. A segunda, referindo-se também a uma feira, esta ocorrida em Nova York, em 1939, 
para expor os avanços tecnológicos americanos, na qual o Brasil também atuou de alguma forma. No primeiro caso, ao enviar para exposição, bonecas representando as mães-de-santo baianas e de imagens representando os orixás da cultura negra, o Museu Nacional teve sua exposição impedida pela organização da feira portuguesa, sob alegação de que "seria deprimente apresentar o Brasil como um país de negros e macumbas". No segundo caso a presença da cantora [branca] Carmen Miranda trajando as roupas da baiana brasileira típica, foi bem recebida nas relações entre Brasil e EUA e amplamente divulgada na mídia da época, diferentemente do caso com as bonecas. (CORRÊA, 2000). Os dois episódios, sumariamente descritos, apresentam de acordo com a perspectiva da autora a imagem de um Brasil que se queria branco, "ainda que incorporando símbolos negros" (: 260). Para resumir a história e, de imediato, relacionar este tema com a questão da mulata exaltada, diz a autora:

(...) a cantora Carmen Miranda corporificou um traço do que depois se convencionou chamar de identidade nacional - a herança africana do país - mas, de maneira análoga à delas, expôs uma relação, nunca explicitada, entre categorias socialmente dominadas em nossa sociedade. Se as relações entre brancos e negros foram sempre vistas aqui como uma relação de dominação, do mesmo modo que as relações entre homens e mulheres, essas mulheres, ao aderirem, de certa forma, ao universo negro - em sendo brancas e, implicitamente, parte do grupo dominante - inverteram essas tipologias dominantes na medida em que tentaram, ou foram bem sucedidas em, mostrar, expor, representar, o avesso delas. Assim, é o negro feminizado - a baiana ou a mulata - que acabará por se tornar um símbolo aceitável do país. (CORRÊA, 2000: 261, grifos meus).

A formulação de Gilberto Freyre com relação ao sistema escravista brasileiro e suas consequências para a 'corrupção' da população, brevemente apresentada na primeira parte do artigo, é aparentemente contrastante com a ideia por ele formulada de uma contribuição negra à formação da "família" brasileira. De modo geral pode-se ter a impressão de que o modo 'harmonioso' com que Gilberto Freyre relata as relações entre negros e brancos não expõe verdadeiramente o sistema político-econômico da casa grande e da senzala. Por 
este motivo é com impressão de quase contradição que nos trechos logo acima vemos Gilberto Freyre retratar a ideia corrente de uma "luxúria africana" a partir da ociosidade e dos abusos causados pelo sistema de colonização portuguesa. Uma maior análise sobre tal hipótese deveria ser empreendida para melhor perceber tais contradições. Em todo caso, comentando Ricardo Benzaquem de Araújo, David Lehmann afirma que muitas contradições foram conscientemente deixadas por Gilberto Freyre em seu texto, evidenciando também o comportamento recalcitrante de Gilberto Freyre ao não se dirigir a ninguém (cientistas sociais, biólogos, literatos) em especial em seu texto, evitando arenas intelectuais e coerências analíticas extremas (LEHMANN, 2008).

É fato que ambos, Gilberto Freyre e Mariza Corrêa, falam de lugares e de percepções diferentes e que nenhum dos dois elabora concretamente - seja no primeiro, pelo total despropósito teórico que isso pareceria a época; seja na segunda, pelo fato de, como coloca a autora, ter suprimido muitos de seus percursos analíticos - o que é, efetivamente, o binômio raça/gênero e o que cada categoria significa individualmente. Colocar numa perspectiva comparativa os trabalhos destes autores, portanto, naquilo que tange especificamente a forma como a questão de gênero ou, mais especificamente, como a relação entre raça e gênero é percebida no contexto de suas obras, é um exercício delicado. Ainda assim existem possibilidades de comparação que, apesar das aparentes distâncias entre os textos, podem render boas discussões.

Inicialmente, porém, para esboçar alguns traços comparativos, poderíamos distinguir o determinismo biológico para falar sobre raça, em Freyre, do discurso marcado pela utilização do conceito de cultura, em Corrêa. Retomando brevemente as construções de Gilberto Freyre sobre a mulata e sobre a miscigenação brasileira, nota-se um salto entre sua percepção e a percepção de Mariza Corrêa. A comparação, evidentemente, não é muito justa pois Gilberto Freyre trata de um problema amplo em sua obra (o desenvolvimento da família brasileira) e, ao mesmo tempo, mobiliza conjuntamente a noção de raça - como determinante de aspectos bio-psico-sociais no sujeito - e a noção de cultura - em 
sua acepção mais propriamente boasiano, retratando as experiências e características herdadas do meio cultural. Embora o autor pense em separar em seu trabalho ambos os conceitos, o encontro destas duas grandes categorias explicativas é marcante em Casa-Grande e Senzala. Nesse sentido, os sujeitos produzidos pela miscigenação brasileira seriam um amálgama de características herdadas nos trópicos com características raciais próprias a cada grupo que participou da 'conquista'. Eis como, portanto, a mulata, a cabocla aparece de modo tão reificado e como possuidora de atributos específicos e (in)desejados no encontro racial, conforme se evidenciou nas citações na primeira parte deste trabalho. É importante comentar, como ressaltou Meucci (2006:209), que a noção de humano em Freyre está propriamente vinculada a uma percepção que é "a um só tempo, produto de sua condição psíquica, biológica, ecológica, cultural e histórica". Esta noção está, não estranha, muito próxima da teorização boasiana sobre a temática ${ }^{16}$, que acaba aproximando a antropologia de campos como a biologia, a linguística, a psicologia. Não sem motivos, a escola que se desenvolveu posteriormente nos EUA, na esteira de Boas, se chamou "Cultura e Personalidade". Meucci afirma ainda:

(...) para Freyre, heranças biológicas, psíquicas aliadas a fatores geográficos, históricos e culturais constituem uma espécie de amálgama inseparável, com que se forma e define o ser humano. Para Freyre, as determinações e os condicionamentos entre estes fatores são recíprocos. Ou seja, para ele, é igualmente válido afirmar que heranças biológicas e geográficas condicionam a organização social e que traços genéticos e configurações espaciais são, também, produto de processos sociais. (2006: 209).

O trabalho de Corrêa, por outro lado, envolvido com um momento histórico outro das ideias antropológicas, não se remete em nenhum momento a características raciais (como aspectos herdados biologicamente) para construir seu texto. Ao mesmo tempo, a noção de cultura com a qual lida já não mais se prende somente ao fato dos sujeitos absorverem de sua experiência real suas

16 Gilberto Freyre foi orientando de Franz Boas (1858-1942) enquanto em seu período de estudos nos EUA. 
características e atributos socialmente desenvolvidos. O que está em jogo aqui, diferentemente de Freyre, é a noção de que a mulata é essencialmente uma construção social, assim como é socialmente construída a própria ideia de "raça". Nota-se aqui uma total sujeição da ideia que se faz da morena (ou de nossa vocação para a morenidade) ao processo histórico que construiu representações e imagens (reiteradas na mídia, na literatura, na música) sobre o que seria a tal mulata. Diz a autora:

(...) a mulata é uma figura engendrada, culturalmente construída num longo processo histórico que a opõe seja às figuras femininas que são moeda corrente em nossas pesquisas, seja às figuras masculinas que se opõem a elas (opondo-se, ao mesmo tempo, ao Branco e ao Negro). (CORRÊA, 1996: 48).

Dizer, porém, que um ou outro fenômeno se dá a partir de uma construção social é quase um truísmo e não expõe, totalmente, a particularidade do discurso da autora nem em que medida se distancia do trabalho de Gilberto Freyre. Como apontou a própria Mariza Corrêa, e eis aí o salto sobre o qual falei anteriormente, saímos de uma concepção da mulata como animal, como produto orgânico, sujeito desejado sexualmente, portador de belezas, nem sempre desejado - em suma, de um "modelo de sexo" - para um "modelo de gênero", onde a mulata se torna uma representação própria de características acalentadas em nossa nacionalidade, onde se torna um modo de ser, de comportar-se, de identificar coisas no mundo (p.48-49). O que Gilberto Freyre fez, nesse sentido, foi apontar uma interpretação da miscigenação - orientada por aportes conceituais específicos - onde a morenidade brasileira não é muito mais que sexo. O que Mariza Corrêa demonstra, em contrapartida, é a "invenção" dessa nossa vocação para a morenidade começando mesmo pela representação dela como "sexo" até chegar a sua representação como "gênero", para evidenciar o quanto manipulamos os aportes conceituais e subjetivos das relações de gênero e de raça em nossa história.

Uma das grandes pensadoras da antropologia brasileira e, importante personagem nos debates sobre relações raciais e relações de gênero, Mariza 
Corrêa foi trazida para este artigo como uma forma de contrapontuar Casa-Grande e Senzala de Gilberto Freyre. Como a própria autora aponta (1996), pareceria haver dois grandes momentos (ou linhagens) no debate em ciências sociais sobre relações raciais: um deles orientado por uma percepção mais racista (do ponto de vista do racismo científico) presente nas formulações de Nina Rodrigues (18621906) e seus sucedâneos e que teria tentado investir na presença do componente africano na sociedade brasileira; e outra, a partir da década de 1930, orientado pelos debates de Gilberto Freyre, que teria, em linhas gerais, abordado a temática da miscigenação, do sincretismo e da miscibilidade brasileiros. (CORRÊA, 2000). Os segundos debates, de acordo com os argumentos apresentados, parecem ter tido maior reverberação na antropologia brasileira do que aqueles primeiros, justamente pela permanência desta exaltação à miscigenação e ao componente 'moreno'. É neste sentido que as considerações de Mariza Corrêa sobre a mulata trazidas para este ensaio parecem oferecer uma perspectiva interessante do interminável debate sobre relações raciais e gênero.

No caso de Gilberto Freyre, por sua vez, não foi produzida uma análise extensa da obra, o que certamente ocuparia um espaço bem maior que este e um tempo ainda maior. Ainda que se tenham trazido várias construções de algumas partes do livro, considerando a dimensão do trabalho, ainda seria pouco para uma verdadeira análise. Em todo caso, como prova o texto de Mariza Corrêa a suposta "vocação para a morenidade", a exaltação da mulata e uma série de outras construções que articulam gênero e raça tem em Gilberto Freyre uma pedra fundamental. Em uma passagem interessante, citada por David Lehmann (2008: 373), Fernando Henrique Cardoso comenta que Casa-Grande e Senzala "continuará navegando, não porque seja preciso, mas porque o colchão de ar que a sustenta é a ideia mitificada de nós mesmos, do Brasil, que é necessária para dar a identidade nacional". Como o próprio Cardoso diria em outra ocasião, ainda que fortemente criticado por ser supostamente "incompleto", o trabalho sugere caminhos, aponta, enfim, pistas que podem auxiliar na construção de interpretações sobre o Brasil (2011: 24). Esta é uma ideia interessante e que, de 
alguma forma, reitera a intenção do presente trabalho, que foi a de apontar questões formuladas na história das ciências sociais, podendo ao mesmo tempo ser úteis a um debate sobre nossa disciplina e sobre nossa(s) ideia(s) de identidade nacional.

\section{REFERÊNCIAS}

CORRÊA, Mariza. Sobre a invenção da mulata. Cadernos Pagu. (6-7), pp. 35-50, 1996.

. O mistério dos orixás e das bonecas: raça e gênero na antropologia brasileira. Etnográfica. Vol. IV (2), 2000, pp. 233-265

CUNHA, Maria C. P. Loucura, gênero feminino. Revista Brasileira de História. São Paulo, v.9, n. 18, p. 121-144, ago./set. 1989.

COELHO, C. M. Indiciarismo, História Íntima e Gênero na Casa-Grande e na Senzala de Gilberto Freyre. In: SINAIS - Revista Eletrônica. Ciências Sociais. Vitória: CCHN, UFES, Edição n.04, v.1, Dezembro, 2008. pp.131-163.

ENGEL, Magali. Psiquiatria e feminilidade. In: DEL PRIORE, Mary (org.). História das mulheres no Brasil. São Paulo: Contexto, 1997, p.322-361.

FREYRE, Gilberto. Casa-grande e senzala. Edição crítica de autoria de Guillermo Giucci, Enrique Rodríguez Larreta e Edson Nery da Fonseca. Paris: ALLCA XX, 2002. 1261 p. Com ilustrações. (Coleção Archivos).

. Casa-grande e Senzala: formação da família brasileira sob o regime da economia patriarcal. Apresentação de Fernando Henrique Cardoso. São Paulo: Editora Global, 2011 (6ª reimp).

GUIMARÃES, Antonio S. A. Social Democracy. In: Jessé Souza; Valter Sinder (Org.). Imagining Brazil. Lexington Books, 2005. pp. 119-140 (Disponível em: http://www.fflch.usp.br/sociologia/asag/Racial\%20Democracy\%20ASAG.pdf).

. Depois da democracia racial. In: Tempo Social. Revista de sociologia da USP. V. 18, n. 2. São Paulo, 2006. pp. 269-287.

LEHMANN, David. Gilberto Freyre: a reavaliação prossegue. Horizontes Antropológicos. Porto Alegre, ano 14, n. 29, p. 369-385, jan./jun. 2008. 
MEUCCI, Simone. Gilberto Freyre e a sociologia no Brasil: da sistematização à constituição do campo científico. Tese de Doutorado em Sociologia. Programa de Pós-Graduação em Sociologia, Universidade Estadual de Campinas. Campinas: 2006.

PACHECO, Ana Cláudia Lemos. Raça, gênero e relações sexual-afetivas na produção bibliográfica das ciências sociais brasileiras - um diálogo com o tema. Afro-Ásia. 34 (2006), 153-188.

WADI, Yonissa Marmitt. Louca pela vida: a história de Pierina. Tese de Doutorado em História. Programa de Pós-Graduação em História, Pontifícia Universidade de São Paulo. São Paulo: 2002. 